\title{
Should a clinical rotation in hematology be mandatory for undergraduate medical students?
}

This article was published in the following Dove Press journal:

Advances in Medical Education and Practice

13 September 2016

Number of times this article has been viewed

Jay Mandan'

Harmeet Singh Sidhu'

Adil Mahmood ${ }^{2}$

'Faculty of Medicine, Imperial College London, London, UK; ${ }^{2}$ Faculty of Life Sciences and Medicine, King's College London, London, UK

\begin{abstract}
Clinical rotations form the foundation of medical education. Medical students in the UK are offered conventional rotations such as cardiology, surgery, and psychiatry as part of their undergraduate curriculum, but a rotation in hematology is not currently mandatory. This paper explores the benefits of a compulsory hematology rotation, and suggests recommendations for its implementation in UK medical school curricula.
\end{abstract}

Keywords: medical education, clinical rotations, hematology

\section{Introduction}

Clinical rotations form an integral part of one's medical education and personal development. Often, it is the first experience students have with respect to core and specialty medicine. In the UK medical schools, conventional rotations offered include those in cardiology, surgery, and psychiatry. On the other hand, exposure to "low-yield" (albeit clinically relevant) specialties, such as hematology, may be insufficient. Hematology as a field is of great clinical relevance, as it deals with a wide range of benign and malignant conditions and provides the opportunity to understand a highly intriguing and diverse area of medicine that is currently leading the way for many scientific advances. Therefore, in this paper we discuss whether the addition of a clinical rotation in hematology should be compulsory for all undergraduate medical students.

\section{Why is this relevant?}

As medical students who have recently completed an intercalated BSc (iBSc) in hematology, we began to appreciate how numerous hematological conditions possess consequences that affect many branches of medicine. Additionally, we have seen that hematological principles form a fundamental part of clinical practice. Although a wide variety of rotations are offered at medical schools, not all students are placed on a hematology rotation program. Consequently, exposure to hematology remains essentially as lecture-based teachings, typically associated as part of a course addressing pathology.

\section{Discussion}

In general, medical students receive insufficient exposure to hematology in the clinical setting. Many patients treated under different specialties, such as oncology, frequently possess underlying hematological pathologies. Since the majority of these patients present acutely, it would be extremely beneficial for students to be able to observe the day-to-day management of such cases. The opportunity to witness the overall
Correspondence: Adil Mahmood Faculty of Life Sciences and Medicine, King's College London, London WC2R 2LS, UK

Tel +4475458I4629

Email adil.mahmood@kcl.ac.uk 
presentation of patients will allow students to understand core principles behind clinical investigations and their ensuing management. A recent study investigating the medical resource utilization in patients with chronic lymphocytic leukemia in the UK showed that patients diagnosed with chronic lymphocytic leukemia had 74.6 visits on average to their general practitioner over a 3.3-year period, and an $8.1 \%$ increase in hospitalizations. ${ }^{1}$ Advancing hematological treatments has resulted in a much better prognosis for these patients, and as a consequence of this, newly qualified doctors are more likely to encounter such patients in hospitals.

As outlined by the General Medical Council, it is important for tomorrow's doctors to "make accurate observations of clinical phenomena", "justify the selection of appropriate investigations", and "select appropriate forms of management". ${ }^{2}$ In a previous study, Jones et $\mathrm{al}^{3}$ reported how well prepared medical graduates felt in certain competencies after medical school. Interestingly, 19.9\% felt "less than competent" in utilizing "laboratory and other diagnostic services". 3 Ultimately, endangered patient safety and increased costs are the potential dangers of such incompetency, which was highlighted by the Centers for Disease Control and Prevention. ${ }^{4}$ Adequate clinical experience is vital to aid understanding of basic diagnostic investigations, subsequently forming the foundation of clinical hematology.

Hematology is predominantly tested as part of a syllabus focused on pathology at medical school. ${ }^{5}$ A range of topics are taught, including routine blood testing (essential for diagnosis and management of anemia and thrombocytopenias), blood film interpretation of both red and white blood cell pathologies, as well as hemostasis and coagulopathies. In light of the universal nature of some of these concepts, a basic understanding of these would lead to an improved clinical acumen across all fields of medicine. Since most medical schools do not assess formal application of these principles in a clinical environment, many graduates often find it difficult to integrate investigative hematological findings with patient symptoms. Clinical experience allows students to comprehend and apply this knowledge in practice, enabling the all-important integration of their learning. Simultaneously, because of the broad nature of this discipline, rotation thereof would also aid in the acquisition of knowledge in other fields (eg, pediatrics and obstetrics). Through the implementation of a compulsory hematology rotation into the medical student curriculum, a more comprehensive appreciation of fundamental hematological principles applicable to many medical situations would be obtained.

The potential counterargument for the introduction of an extra compulsory hematology rotation is that there are simply not enough specialized hematological centers available for universities to accommodate all their students. In addition, the financial and administrative pressures associated with the organization of such a rotation are not to be underestimated. However, as mentioned earlier, multidisciplinary interaction has allowed students to experience some form of hematology in many other medical specialties; therefore, this may provide a natural path for universities to introduce a short yet condensed hematology rotation during the course of undergraduate clinical training, which spans a period of 3 academic years.

While we understand the logistical burden and resource allocation strain that an extra rotation may have on a medical school, it is our shared opinion that the benefits to students far outweigh these disadvantages. Moreover, such an action would provide the prospect of a unified learning experience, as hematologists are both trained clinicians and pathologists. In order to achieve the best hematology learning experience for students, we need to consider a broader solution, such as one proposed by $\mathrm{Chu}$ et $\mathrm{al}^{6}$ for the integration of pathology into clinical rotations. Therefore, while we agree that a hematology rotation in medical school is necessary, we feel that relevant hematological pathologies should be integrated and explored in other clinical rotations. Moreover, implementation of Ford and Pambrun's ${ }^{7}$ exit competencies, or a similar variant, would be extremely useful to set a universal benchmark for medical students. The following provides a framework by which the benefits of clinical hematology can be maximized:

1. Added hematology-based focus in current clinical rotations: Students must appreciate the importance of basic hematological principles, and the multidisciplinary nature of hematology means current clinical rotations provide the ideal platform to reinforce these. For example, students taking blood samples from core rotations should complete the cycle of the investigation; this would involve going to the laboratory and following the patient up after the results have become available. It is important for students to appreciate what happens to a blood sample after it is taken, including its analysis and processing times. Students on an oncology rotation should have some protected time with a hematologist-oncologist, who should highlight particularly interesting patients to monitor. Specific learning opportunities from this rotation include hematological malignancies, stem-cell transplant, chemotherapy, and radiotherapy. Similarly, students on a pediatric rotation should be allocated some protected time with a pediatric hematologist. As well as hematological malignancies, students have a chance to experience how 
hemoglobinopathies are managed. This is also a good opportunity to consolidate knowledge of blood films and hemoglobin electrophoresis.

2. Dedicated hematology rotation: This will allow students to integrate their knowledge and experience of hematology into a categorical rotation. They should be allocated laboratory time to experience a range of hematological pathologies for reasons already mentioned. A dedicated rotation will also allow students to learn basic skills required by foundation doctors (ones which may not necessarily be assessed at medical school) such as fluid management, hemostasis prophylaxis, and transfusion medicine (including blood typing and crossmatching).

\section{Conclusion}

Although further reviews are needed to establish both the most beneficial teaching methodologies for medical students and a targeted needs assessment, we firmly believe the addition of a clinical rotation dedicated to hematology is likely to produce more competent and confident doctors in the future.

\section{Author contributions}

$\mathrm{JM}$ - concept, literature review and drafting manuscript. HSS - literature review and drafting manuscript. AM - literature review, drafting and submission. All authors contributed toward data analysis, drafting and critically revising the paper and agree to be accountable for all aspects of the work.

\section{Disclosure}

The authors report no conflicts of interest in this work.

\section{References}

1. Pfeil AM, Imfeld P, Pettengell R, et al. Trends in incidence and medical resource utilisation in patients with chronic lymphocytic leukaemia: insights from the UK Clinical Practice Research Datalink (CPRD). Ann Hematol. 2015;94(3):421-429.

2. General Medical Council. Tomorrow's doctors: outcomes and standards for undergraduate medical education. General Medical Council; 2009 [cited April 25, 2016]. Available from: Archived by WebCite ${ }^{\circledR}$ at http:// www.webcitation.org/6h2dJsVuu. Accessed August 18, 2016.

3. Jones A, McArdle PJ, O'Neill PA. Perceptions of how well graduates are prepared for the role of pre-registration house officer: a comparison of outcomes from a traditional and an integrated PBL curriculum. Med Educ. 2002;36(1):16-25.

4. Division of Laboratory Systems, Centers for Disease Control and Prevention. Laboratory medicine: national status report. Centers for Disease Control and Prevention; 2008 [cited April 26, 2016]. Available from: Archived by WebCite ${ }^{\circledR}$ at http://www.webcitation.org/6h442Oeba. Accessed August 18, 2016.

5. Emerson PM. Haematology: is it well taught? J R Soc Med. 1991;84(6): 336-337.

6. Chu Y, Mitchell RN, Mata DA. Using exit competencies to integrate pathology into the undergraduate clinical clerkships. Hum Pathol. 2016; 47(1):1-3.

7. Ford J, Pambrun, C. Exit competencies in pathology and laboratory medicine for graduating medical students: the Canadian approach. Hum Pathol. 2015;46(5):637-642.
Advances in Medical Education and Practice

\section{Publish your work in this journal}

Advances in Medical Education and Practice is an international, peerreviewed, open access journal that aims to present and publish research on Medical Education covering medical, dental, nursing and allied health care professional education. The journal covers undergraduate education, postgraduate training and continuing medical education

\section{Dovepress}

including emerging trends and innovative models linking education, research, and health care services. The manuscript management system is completely online and includes a very quick and fair peer-review system. Visit http://www.dovepress.com/testimonials.php to read real quotes from published authors. 